\title{
Representación fotográfica de las atletas en la prensa deportiva digital española durante los Juegos Olímpicos de Río
}

\section{The photographic representation of female athletes in the Spanish digital sport press during the Rio Olympic Games}

\section{Representação fotográfica dos atletas na imprensa desportiva digital espanhola durante os Jogos Olímpicos do Rio}

Ana M. Muñoz-Muñoz, Universidad de Granada, Granada, España (anamaria@ugr.es)

Juana Salido-Fernández, Universidad de Granada, Granada, España (juanasalido@correo.ugr.es)

RESUMEN | Este artículo estudia la representación de las imágenes femenina y masculina en la prensa deportiva digital española durante los Juegos Olímpicos de Río 2016 para desvelar si existe un encuadre visual diferenciado de género. Se analiza el contenido de 3738 noticias a través de ocho variables: género del protagonista, cantidad y tamaño de las fotografías, tipo de deporte, contenido de las imágenes, acción del protagonista, presencia de sesgos o estereotipos de género y sus tipologías. Los hallazgos muestran una infrarrepresentación en la cobertura visual del deporte femenino y su trivialización mediante un encuadre noticioso ambivalente: aunque de forma general no ofrece un contexto diferenciado de género, tiende a representar a las deportistas en mayor medida en disciplinas consideradas apropiadas en función de su sexo y de una forma pasiva. Asimismo, se ha encontrado una cierta presencia de sesgos y estereotipos de género mediante marcos de sexualización y belleza, imágenes degradantes y mayor énfasis en las emociones, en la maternidad y la vida familiar femeninas. Todo ello puede sesgar la percepción de la audiencia, que puede valorar el deporte femenino como menos relevante que el masculino.

PALABRAS CLAVE: mujeres; medios; deporte; fotografía; prensa deportiva; prensa digital; Juegos Olímpicos; encuadre fotográfico. 
ABSTRACT/This paper studies the representation offemale and male images in the Spanish digital sport press during the 2016 Olympic Games to show if the visual framework is different for each gender. We conducted a content analysis of 3738 news items througheight different variables: athlete's gender, photographs' quantity and size, sport, image content, action of the protagonist, presence of gender biases or stereotypes and their typology. Findings show that there is an underrepresentation of female visual coverage and a trivialization of women's sports with visual ambivalence in the images. This is because, even though there is not a differentiated context by gender, media tends to represent female athletes in so-called gender-appropriate sports and in a passive way. In addition, we found gender biases and stereotypes derived from frames of sexualization and beauty, degrading images, greater emphasis on female emotions, motherhood, and family life. All of this can impact the audience's perception as they understand that women's sports are less relevant than men's.

KEYWORDS: women; media; sport; photograph; sport press; digital press; Olympic Games; photographs frames.

RESUMO | Este artigo estuda a representação das imagens femininas e masculinas na imprensa desportiva digital espanhola durante os Jogos Olímpicos do Rio 2016 para revelar se há umenquadramento visual diferenciado por gênero. É realizada uma análise de conteúdo de 3738 notícias através de oito variáveis diferentes: sexo do protagonista, número e extensão das fotografias, tipo de esporte, conteúdo das imagens, ação realizada pelo protagonista, presença de preconceitosou estereótipos de gênero e suas tipologias. Os resultados mostram que existe uma sub-representação de cobertura visual do esporte feminino e uma banalização através de um quadro noticioso ambivalente, embora em geral não ofereça um contexto diferenciado por género, tende a representar as mulheres atletas em maior medida em disciplinas consideradas apropriadas de acordo com o seu sexo e de uma forma passiva. Além disso, foi encontrada uma certa presença de preconceitos e estereótipos de gênero através dos quadros de sexualização e beleza, imagens degradantes e maior ênfase nas emoções femininas, na maternidade e a vida familiar. Tudo isto pode afetar a percepção do público ao compreender que o esporte feminino é menos relevante do que o masculino.

PALAVRAS-CHAVE: mulheres; meios de comunicação; esporte; fotografia; imprensa esportiva; imprensa digital; Jogos Olímpicos; enquadramento fotográfico. 


\section{INTRODUCCIÓN Y ESTADO DE LA CUESTIÓN}

Las imágenes han sido descritas como objetivas y verdaderas, espejos de los eventos que representan, debido a la "verosimilitud fotográfica" (Zelizer, 2005, p. 171) que refuerza el mito de naturalidad capturada mecánicamente. Estas no registran la verdad objetiva, pues representan eventos, contextos y participantes que son recortados, retocados y enmarcados (Barthes, 1977). Las imágenes, construcciones culturales, producen visiones específicas de las diferencias raciales, sociales o sexuales que son mostradas como universales y transmitidas a través de los medios de comunicación (Rose, 2012). Así, al difundir y reforzar las diferencias sexuales (Goffman, 1974), pueden producir otredad y reproducir relaciones patriarcales mediante estereotipos de género (Duncan, 1990).

En las sociedades occidentales, las diferencias biológicas entre los sexos han dado lugar a una construcción sociocultural de lo femenino y de lo masculino basada en atribuir roles de género diferenciados (Hargreaves \& Anderson, 2014), lo que produce una jerarquización. El varón y lo masculino son asociados con la fuerza física, la agresividad o la potencia, llevándolos a dominar actividades como el deporte. Para Ramón-Vegas (2012), esta institución es construida social y simbólicamente por una hegemonía masculina que naturaliza, preserva y privilegia su poder. El rol masculino es complementado con un rol femenino asociado con la dependencia y la subordinación al varón, así como con la debilidad física, la pasividad y la belleza, que ha excluido históricamente a las mujeres de la práctica deportiva, accediendo a aquellos deportes considerados apropiados para ellas, como la gimnasia o el tenis, al estar basados en cualidades menos físicas y más estéticas (Alfaro et al., 2011). Estos roles son naturalizados, reproducidos y perpetuados por los medios de comunicación deportivos, cuando difunden estereotipos de género que infrarrepresentan y trivializan el deporte femenino (Salido-Fernández \& Muñoz-Muñoz, 2021a).

Las imágenes mediáticas pueden hacer que los espectadores se identifiquen con aquello que ven, como el éxito de un deportista, otorgándole poder al presentarlo como triunfador, fuerte y activo y ver integrarse en él los atributos asociados con el deporte y la masculinidad (Borcila, 2000). También puede otorgar al consumidor una posición de poder y dominación cuando las mujeres son presentadas en las imágenes como seres emocionales, pasivos y débiles ante lesiones (Smith \& Bissell, 2014). Se las muestra bellas, con poses sugerentes, de forma sexualizada (King, 2007) y como objeto de deseo para la audiencia masculina (Muñoz-Muñoz \& SalidoFernández, 2018). En un mundo organizado a partir del desequilibrio sexual, el placer de mirar se divide entre lo activo-masculino y lo pasivo-femenino, donde las mujeres son vistas y exhibidas simultáneamente, haciendo que su apariencia esté codificada según la mirada masculina con un fuerte impacto visual y erótico (Mulvey, 1999, p. 837). Así, para aparecer en los medios deben cumplir unos cánones 
de belleza, lo que según Weber y Carini (2013) las convierte en objeto de consumo, las desvaloriza y limita su desarrollo profesional, determinando el lugar que van a ocupar tanto en el deporte como en la sociedad.

Los estudios sobre la representación fotográfica femenina en la cobertura deportiva encuentran una notable falta de equidad, en la cantidad de imágenes, el tamaño y su posición (King, 2007). Las mujeres quedan marginadas, excluidas o infrarrepresentadas de la cobertura visual (Fink \& Kensicki, 2002) y sus logros son invisibilizados o están distorsionados, lo que implica su aniquilación simbólica (Tuchman, 1978). Las primeras investigaciones sobre las imágenes deportivas, en los años noventa, encuentran el triple de fotografías masculinas que femeninas (Duncan, 1990). A principios de 2000, Pedersen (2002) y Vincent (2004) encuentran una cobertura femenina de entre 30\%-39\% y a finales de esa década, en torno a $42 \%$ (King, 2007). En los últimos años se aprecian grandes diferencias entre la escasa cobertura diaria de los medios deportivos tradicionales y en línea (Weber \& Carini, 2013) y la de grandes eventos como los Juegos Olímpicos, que parecen ofrecer mayor nivel de equidad, con alrededor de 40-45\% de cobertura visual femenina (Godoy-Presland \& Griggs, 2014; Dafferner et al., 2019). Estos datos están más en línea con el porcentaje de participación deportiva femenina en los Juegos de Tokio 2020, que alcanzó 49\% (“Trailblazing Tokio...", 2020), mejora que se produciría en parte debido al carácter nacionalista del evento, en el que cada país tiende a sobrerrepresentar a sus atletas (Delorme \& Testard, 2015).

La investigación desarrollada en España también percibe ese incremento. Sanz Garrido (2015) lo encuentra en la prensa nacional y regional durante los Juegos de Londres 2012, con 44\% de presencia de atletas femeninas en Marca (https://www. marca.com/). La autora también percibe una notable presencia de estereotipos de género asociados con la belleza y las emociones femeninas, más cobertura de deportes considerados apropiados femeninos e imágenes estereotipadas. Los medios digitales, a pesar de su capacidad para innovar, siguen las mismas pautas de los tradicionales en la representación de género (Franquet et al., 2006). En esta línea, Perrino Pena y Pascual Fibla (2019) encuentran en la cobertura de Río 2016 una falta de equidad en la representación y el mantenimiento de un contenido discriminatorio (Ada-Lameiras, 2019); en las redes sociales de los medios generalistas y deportivos existe una estereotipación femenina a través de imágenes asociadas con la belleza y glamur. Asimismo, el contenido que las concierne es de carácter sexualizado (Salido-Fernández \& Muñoz-Muñoz, 2021b).

Las imágenes femeninas son examinadas cada vez más desde estudios cualitativos para profundizar en otros aspectos, como el tipo de fotografía, su ubicación, el enfoque o encuadre empleado. Ello permite desvelar si la forma en la 
que se construyen se diferencia en función del sexo de su protagonista (Pedersen, 2002; Berstein \& Kian, 2013; Litchfield \& Kavanagh, 2019).

\section{Teoría del encuadre}

Los encuadres o marcos (frame) remiten a aspectos de la realidad percibida en texto o imágenes que son resaltados al comunicar por encima del resto (McCombs, 2006). Quien encuadra disfruta de mayor agencia que las personas encuadradas (Goffman, 1974), lo que puede crear puntos de vista y estereotipos sobre grupos en función de su sexo, raza o clase, que influyen en lo que piensan y deciden los consumidores (Hardin et al., 2002). Los medios asumen el valor estratégico de establecer de qué se habla y cómo se habla, transmitiendo narrativas que quedan arraigadas culturalmente y en el tiempo (Reese, 2001). Los trabajos de encuadre se centran en seleccionar, enfatizar, repetir y excluir palabras o imágenes (Tankard, 2001; Angelini \& Billings, 2010). De allí su utilidad para estudiar la representación de los sexos en los medios y los patrones de contenido empleados en los medios deportivos (Berstein \& Kian, 2013). En el caso de las imágenes, estas dan cuenta de cómo es el mundo (o cómo debería ser, según el fotógrafo) y pueden llegar a influir más en las audiencias que los marcos verbales, al tener un impacto mayor y más rápido que el texto (Dixon, 2008). Influyen aspectos como el tamaño, su ubicación en el medio, su color y el ángulo de la cámara, así como las expresiones faciales, posturas y movimientos de sus protagonistas (Coleman, 2010; Godoy-Pressland \& Grigg, 2014). Los trabajos sobre marcos visuales en los medios encuentran una evolución de un sexismo más evidente y degradante a uno más suave o blando (Jones, 2003; Musto et al., 2017), pero que igualmente invisibiliza a las mujeres, normaliza la jerarquía y refuerza las diferencias sexuales en el deporte (Fink \& Kensicki, 2002; Hardin et al., 2002). Para ello, se utilizan mecanismos de ambivalencia (Berstein \& Kian, 2013; Cranmer et al., 2014). Se emiten mensajes contradictorios de una forma sutil, que hace que pasen inadvertidos, por ejemplo celebrando, pero a la vez trivializando y restando importancia a un triunfo del deporte femenino (Cranmer et al., 2014). Esta ambivalencia también resta poder a las mujeres en el deporte mediante fotografías que refuerzan la feminidad, la vulnerabilidad, la dependencia, la emoción o la sexualidad femenina entre otros muchos marcadores tradicionales de género (Smith \& Bisell, 2014). Se muestran mujeres como pasivas y débiles, con posturas estéticas e inmóviles (Fink \& Kensicki, 2002; Lynn et al., 2004; Litchfield \& Kavanagh, 2019), empleando planos más cercanos centrados en la estética del individuo y no tanto en su actividad deportiva (Hardin et al., 2005; Jones, 2006). Los encuadres que ponen el foco en el deporte femenino son escasos (Berstein \& Kian, 2013). Estos estudios encuentran que las deportistas son socavadas mediante el ángulo de la imagen, mostradas en plano picado y mirando al suelo, lo que reduce su poder frente a los planos contrapicados, que favorecen la superioridad del deportista 
(Duncan, 1990; Hardin et al., 2002). La producción técnica de la cobertura de los eventos, los ángulos de la cámara, los tipos de disparos y efectos especiales pueden influir en el interés del espectador, como en los Juegos Olímpicos de Atenas 2004 (Greer et al., 2009), con mayor presencia y variedad de esta en la cobertura masculina. Así, se habla de una construcción técnica del evento diferente según el sexo (Borcila, 2000), haciendo que la audiencia vea la cobertura femenina como naturalmente menos interesante y visualmente menos emocionante que la masculina. Bissell y Duke (2007) analizan los ángulos de las imágenes del voleibol playa femenino en esos mismos juegos y descubren que las deportistas son objetivadas, al mostrarse repetidamente primeros planos de sus pechos y nalgas. Por su parte, Delorme y Testard (2015) ven mayores niveles de equidad en aspectos como la postura, los ángulos de cámara o los deportes durante la cobertura de los Juegos de Londres 2012 en la prensa francesa, aunque perciben una clara subrepresentación femenina en las imágenes. Otros investigadores encuentran en distintos Juegos Olímpicos que se prioriza la cobertura de deportes estéticos e individuales femeninos, como el patinaje o la gimnasia, frente a otros de equipo y basados en el contacto físico, como el fútbol o el hockey, considerados masculinos (Koivula, 1999; Jones, 2006; Coche \& Tuggle, 2017). Todo ello afecta el interés y la percepción de los espectadores, que ven una cobertura femenina que resalta más otros aspectos que los deportivos (Weber \& Carini, 2013). Así, se le resta valor al logro deportivo femenino, visto como menos relevante que el masculino (Davis \& Tuggle, 2008). Ello impide desarrollar referentes para niñas y jóvenes (López-Diez, 2011) y fomenta perfiles objetivados femeninos destinados al mero entretenimiento de la audiencia masculina (MuñozMuñoz \& Salido-Fernández, 2018); todo lo anterior, a pesar del contexto actual de mayor participación deportiva femenina (Godoy-Pressland \& Griggs, 2014).

En esa línea, este trabajo examina la representación fotográfica de las atletas en los medios digitales deportivos españoles de mayor audiencia durante los Juegos Olímpicos de Río 2016, para ver si se percibe mayor equidad de género en las imágenes, tanto en la cantidad como en el contenido de la cobertura, y si existe un encuadre visual de género diferenciado.

Se plantean las siguientes hipótesis:

H1. La cobertura de las imágenes refleja una participación desigual de cada sexo, tanto en número como en extensión.

H2. Las atletas tienen mayor cobertura visual en deportes considerados como apropiados femeninos y los atletas, en los apropiados masculinos.

H3. Los atletas están sobrerrepresentados en imágenes deportivas y las atletas, en contextos extradeportivos. 
H4. Las deportistas son mostradas en mayor medida en actitud pasiva y los deportistas, de forma activa.

H5. Las imágenes femeninas contienen más sesgos y estereotipos de género que las masculinas.

\section{METOdOLOGÍA}

Se recopilaron las noticias publicadas entre el 5 y 21 de agosto de 2016 sobre los Juegos Olímpicos de Río en las webs de los cuatro diarios digitales deportivos de mayor lectoría en España, que cuentan con sus respectivas ediciones en papel: Marca (4547 millones de usuarios únicos diarios en 2016), As (con 2246), Sport (1281) y Mundo Deportivo (1195) (https://reporting.aimc.es/index.html\#/main/internet). Se emplearon palabras clave en las casillas de búsqueda: Juegos Olímpicos, JJOO, Juegos Olímpicos Río y Río 2016, eliminando las duplicidades y noticias de ediciones diferentes. De las 5108 informaciones obtenidas se seleccionó manualmente una muestra intencional, que contuviesen al menos una fotografía y cuyo protagonista fuese un deportista varón o mujer, español o extranjero ( $\mathrm{N}=3738$ ), descartándose noticias con otros elementos visuales como gráficos o vídeos, así como las referidas a ambos sexos. Tampoco se contabilizó el número de atletas en cada imagen.

Se realizó un análisis de contenido mixto (Krippendorf, 1990) aplicado a la información deportiva (Andrew et al., 2011) para contabilizar la cantidad de cobertura visual total por sexos, y conocer las representaciones de género en las imágenes de manera cualitativa (Bryman, 2016). Solo se analizó la imagen principal de cada noticia, para que los datos de cada una fuesen excluyentes. Este tipo de análisis permite decodificar los mensajes, para esclarecer patrones de representación en los medios (Strinati, 2000) y para describir de forma sistémica y objetiva el contenido de los mensajes y de las imágenes de grupos oprimidos históricamente (Hardin et al., 2002). En cuanto a los límites, no podemos conocer la intención de los productores de estos contenidos o la ambigüedad con la que estos medios pueden representar a cada sexo.

La codificación, clasificación y análisis de los datos utilizó el programa estadístico IBM SPSS v.24. Ambos investigadores codificaron manualmente y de forma independiente los datos mediante un sistema de categorías confiables, mutuamente excluyentes, predeterminadas y exhaustivas a partir de un formulario de codificación basado en los trabajos de Billings y Eastman (2003), adaptados al objetivo de la investigación (Wimmer \& Domminick, 2011) y se adoptó un enfoque inductivo en las noticias que no encajaban en las categorías existentes.

Se establecieron ocho variables (tabla 1). 


\begin{tabular}{cc}
\hline Sexo del protagonista & Contenido de la fotografía \\
\hline Tipo de deporte & Acción del protagonista de la imagen \\
\hline Número de fotografías & ¿Se perciben sesgos o estereotipos? \\
\hline Tamaño de las fotografías $\left(\mathrm{en}^{\mathrm{c}} \mathrm{cm}^{2}\right)$ & Tipología de estereotipos presentes \\
\hline
\end{tabular}

Tabla 1. Clasificación de las variables analizadas

Categorías de estereotipos

Roles tradicionales

(López-Diez, 2011)

Expresión de las emociones (Borcila, 2000)

Comunicación no verbal (Bisell \& Duke, 2007)

Noticias sobre deportistas mujeres

\section{Descripción}

Femeninos: belleza, maternidad, cuidado familiar. Masculinos: violencia y agresividad

Protagonista llora, muestra debilidad o vulnerabilidad física o mental

Expresiones o posturas vejatorias o humillantes que denigran al protagonista (por ejemplo: una mueca extraña

Ausencia de imágenes femeninas

Marco de sexualización

Tabla 2. Categorías de estereotipos presentes en las imágenes analizadas

Fuente: Elaboración propia.

El contenido de la fotografía se codificó en base a si la imagen se produce en un contexto deportivo o no deportivo (Fink \& Kensicki, 2002) ( 0 =imagen deportiva; $1=$ no deportiva). Un deportista anotando un gol se considera imagen deportiva y el mismo visitando la ciudad, no. Si el contexto no era suficientemente claro para clasificarla, se consideraron los accesorios (entorno deportivo o ropa). Otra variable es la acción del protagonista ( $0=$ activa; $1=$ pasiva; $2=$ no procede), es decir, si se muestra a los atletas compitiendo o entrenando o, por el contrario, inmóvil posando frente a la cámara (Pedersen, 2002; Delorme \& Testard, 2015); no procede se utiliza para las fotografías en las que no se aprecia la actividad que desempeñan. En último lugar, se establece si la imagen tiene sesgos o estereotipos de género ( $0=$ =sí, $1=$ no, $2=$ no procede/no se aprecia) y si sí, qué estereotipos muestran, en las siguientes categorías (tabla 2).

Para la última categoría se codificaron tres subcategorías: exposición de la piel, es decir, si el atleta aparece desnudo, semidesnudo o completamente vestido (Fink \& Kensicki, 2002; Daniels \& Wartena, 2011); la posición del cuerpo, referido a mostrar una pose sexualmente sugerente o no (Duncan, 1990), y el ángulo de la cámara, esto es, si la imagen ofrece alguna parte del cuerpo como punto focal adonde se dirija la mirada del público. Este será considerado inapropiado cuando la atención recaiga en partes del cuerpo como glúteos o pechos (Bisell \& Duke, 2007; Cranmer et al., 2014; Wasike, 2017). 
Se empleó la estadística descriptiva con tablas de frecuencias y porcentajes, inferenciales, cruzadas y de contingencia, así como pruebas chi-cuadrado de Pearson de significación estadística no paramétrica (Wimmer \& Dominick, 2011), para medir diferencias significativas entre las unidades de información esperada y observada ( $<<0,0001)$. Para cuantificar la cobertura eliminando posibles sesgos metodológicos, se utilizó la participación de los atletas como estándar independiente. Este "refleja la proporcionalidad de la cobertura en relación con el número de atletas participantes de géneros específicos" (Eagleman et al., 2014, p. 463).

Se calculó la fiabilidad entre los dos codificadores del 16,5\% de la muestra (600 noticias en total), con el coeficiente Kappa de Cohen, considerando aceptable una superposición de datos de entre un 10-20\% (Riffle et al., 2005). Las variables obtuvieron coeficientes Kappa superiores a ,75, un rango de confiabilidad aceptable.

\section{RESULTADOS}

\section{Cantidad de cobertura fotográfica}

Para demostrar la primera hipótesis sobre una mayor cobertura masculina que femenina en las noticias e imágenes se utilizó como estándar independiente la participación de cada sexo en los Juegos ( $\mathrm{n}=5,059$ mujeres y $\mathrm{n}=6,179$ hombres; https://olympics.com/en/olympic-games/rio-2016). Una cobertura equilibrada reflejaría la proporcionalidad entre el número de participantes de cada sexo y la cobertura recibida (Eagleman et al., 2014). Del total de 11.238 atletas, el 45\% fueron mujeres y el 55\% hombres. Para el caso español (309 atletas), participaron 165 hombres (53,4\%) y 144 mujeres (46,5\%) (Comité Olímpico Español, 2016). Al combinar los datos de participación con la cobertura general, se encuentra que del total de noticias analizadas $(\mathrm{n}=3738)$ las mujeres apenas alcanzaban el $34 \%$ $(\mathrm{n}=1271)$ y los hombres un 66\% ( $\mathrm{n}=2467)$ (tabla 3$)$.

\begin{tabular}{ccccccc}
\multirow{2}{*}{ Sexo } & \multicolumn{2}{c}{ Participación } & \multicolumn{2}{c}{ Cobertura } & \multicolumn{2}{c}{ Cobertura visual } \\
\cline { 2 - 7 } & $\mathbf{N}^{\mathbf{0}}$ & $\%$ & $\mathbf{N}^{\mathbf{0}}$ & $\%$ & $\mathbf{N}^{\mathbf{0}}$ & $\%$ \\
\hline Mujeres & 5059 & 45,02 & 1271 & 34,01 & 2464 & 30,78 \\
\hline & & & & & $(-1139)$ & $(-15 \%)$ \\
\hline Hombres & 6179 & 54,98 & 2467 & 65,99 & 5539 & 69,21 \\
\hline & & & & & $(+1139)$ & $(+15 \%)$ \\
\hline TOTAL & 11.238 & 100 & 3738 & 100 & 8003 & 100 \\
\hline
\end{tabular}

Tabla 3. Cantidad de cobertura de noticias e imágenes por sexo

Fuente: Elaboración propia. 


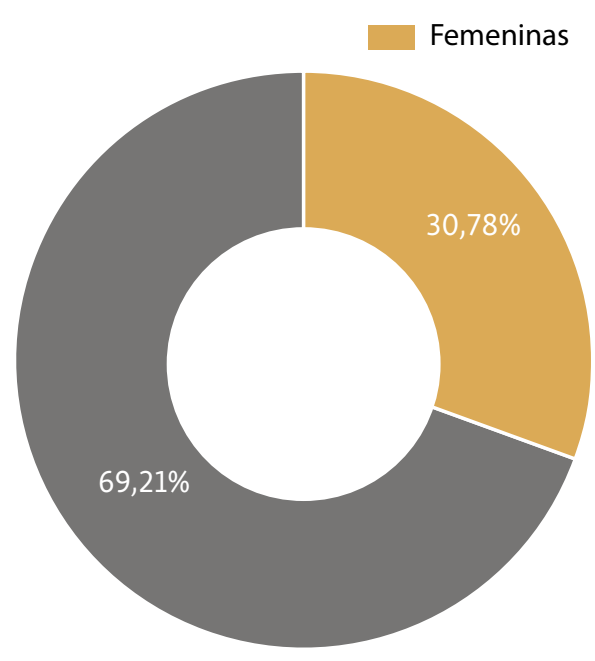

Figura 1. Cantidad de imágenes por sexo

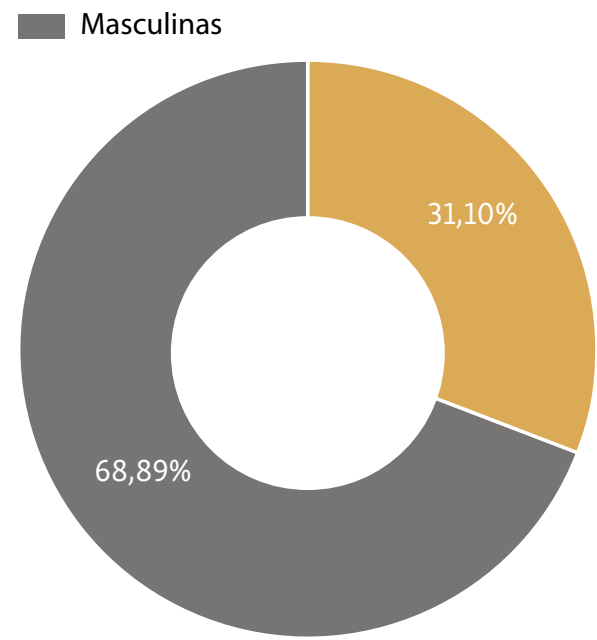

Figura 2. Extensión de las imágenes por sexo

Fuente: Elaboración propia.

En cuanto a la cantidad de imágenes ( $\mathrm{n}=8003)$ ), (figura 1), el 30,78\% (2464) son femeninas y el $69,21 \%$, masculinas $(n=5539)$, lo que supone una variación de los resultados esperados en función del índice de participación de -15\% en el caso femenino $\mathrm{y}+15 \%$ en el masculino. En cuanto al total $\mathrm{de}^{\mathrm{cm}}{ }^{2}$ (figura 2), la superficie total de imágenes femeninas alcanzaría los $582.859,50 \mathrm{~cm}^{2}(31,10 \%)$ y la masculina los $1.290 .693,55 \mathrm{~cm}^{2}(68,89 \%)$.

\section{Presencia de tipo de deportes considerados apropiados para cada sexo}

Para el tipo de deporte se recopila la clasificación de los diez eventos deportivos con mayor cobertura (tabla 4), para comparar en función del sexo. El baloncesto, el atletismo y el tenis son los tres deportes con mayor número de noticias e imágenes (57,3\%), seguidos de la natación (9,2\%) y el fútbol (6,6\%). En las últimas posiciones están el balonmano y el bádminton, por debajo del $2 \%$ de cobertura visual cada uno.

Si comparamos esta tabla general con la siguiente (tabla 5), que ilustra los deportes de mayor cobertura por sexo, los tres más seguidos se corresponden con los tres primeros masculinos. En siete de los diez deportes con mayor interés mediático los hombres superan en número de noticias e imágenes a las mujeres, salvo en natación, aunque con datos muy similares en las imágenes ( $4,6 \%$ femenino y $4,5 \%$ masculino), pese a que el equipo español consiguió dos medallas femeninas y ninguna masculina.

Lo mismo ocurre con los dos deportes con menor cobertura visual en la tabla general, el balonmano ( $1 \%$ femenino y 0,1\% masculino), sin participación del equipo masculino español y el femenino obtuvo un diploma olímpico y el bádminton ( $1,5 \%$ femenino frente al $0,1 \%)$, con dos participantes españoles, uno de cada sexo y medalla de oro femenina. 


\begin{tabular}{ccccc} 
& \multicolumn{2}{c}{ Total noticias } & \multicolumn{2}{c}{ Total imágenes } \\
\cline { 2 - 5 } Disciplina deportiva & $\mathbf{N}^{\mathbf{0}}$ & $\%$ & $\mathbf{N}^{\circ}$ & $\%$ \\
\hline Baloncesto & 723 & 19,3 & 2714 & 34,0 \\
\hline Atletismo & 525 & 14,0 & 1058 & 13,2 \\
\hline Tenis & 348 & 9,3 & 811 & 10,1 \\
\hline Natación & 338 & 9,0 & 734 & 9,2 \\
\hline Fútbol & 247 & 6,7 & 530 & 6,6 \\
\hline Waterpolo & 96 & 2,6 & 105 & 1,3 \\
\hline Boxeo & 85 & 2,3 & 125 & 1,6 \\
\hline Hockey césped & 83 & 2,2 & 105 & 1,3 \\
\hline Piragüismo aguas tranquilas & 82 & 2,2 & 157 & 2,0 \\
\hline Balonmano & 78 & 2,1 & 91 & 1,1 \\
\hline Bádminton & 78 & 2,1 & 136 & 1,7 \\
\hline Resto de deportes & 1055 & 28,2 & 1437 & 17,9 \\
\hline Total & 3738 & 100 & 8003 & 100 \\
\hline
\end{tabular}

Tabla 4. Diez eventos deportivos con mayor cobertura

Fuente: Elaboración propia.

\begin{tabular}{|c|c|c|c|c|c|c|}
\hline \multirow{2}{*}{ Sexo } & & \multirow{2}{*}{ Deporte } & \multicolumn{2}{|c|}{ Total noticias } & \multicolumn{2}{|c|}{ Total imágenes } \\
\hline & & & $\mathbf{N}^{\circ}$ & $\%$ & $\mathrm{~N}^{\circ}$ & $\%$ \\
\hline \multirow{11}{*}{ Hombres } & $1^{\circ}$ & Baloncesto & 582 & 15,6 & 1635 & 20,4 \\
\hline & $2^{\circ}$ & Atletismo & 363 & 9,7 & 794 & 9,9 \\
\hline & $3^{\circ}$ & Tenis & 266 & 7,1 & 713 & 8,9 \\
\hline & $4^{\circ}$ & Fútbol & 217 & 5,8 & 495 & 6,2 \\
\hline & $5^{\circ}$ & Natación & 157 & 4,2 & 364 & 4,5 \\
\hline & $6^{\circ}$ & Boxeo & 79 & 2,1 & 114 & 1,4 \\
\hline & $7^{\circ}$ & Piragüismo (aguas tranquilas) & 71 & 1,9 & 145 & 1,8 \\
\hline & $8^{\circ}$ & Waterpolo & 58 & 1,6 & 63 & 0,8 \\
\hline & $9^{\circ}$ & Hockey césped & 55 & 1,5 & 74 & 0,9 \\
\hline & $10^{\circ}$ & Golf & 54 & 1,4 & 73 & 0,9 \\
\hline & & Resto de deportes & 554 & 14,8 & 1046 & 13,1 \\
\hline
\end{tabular}




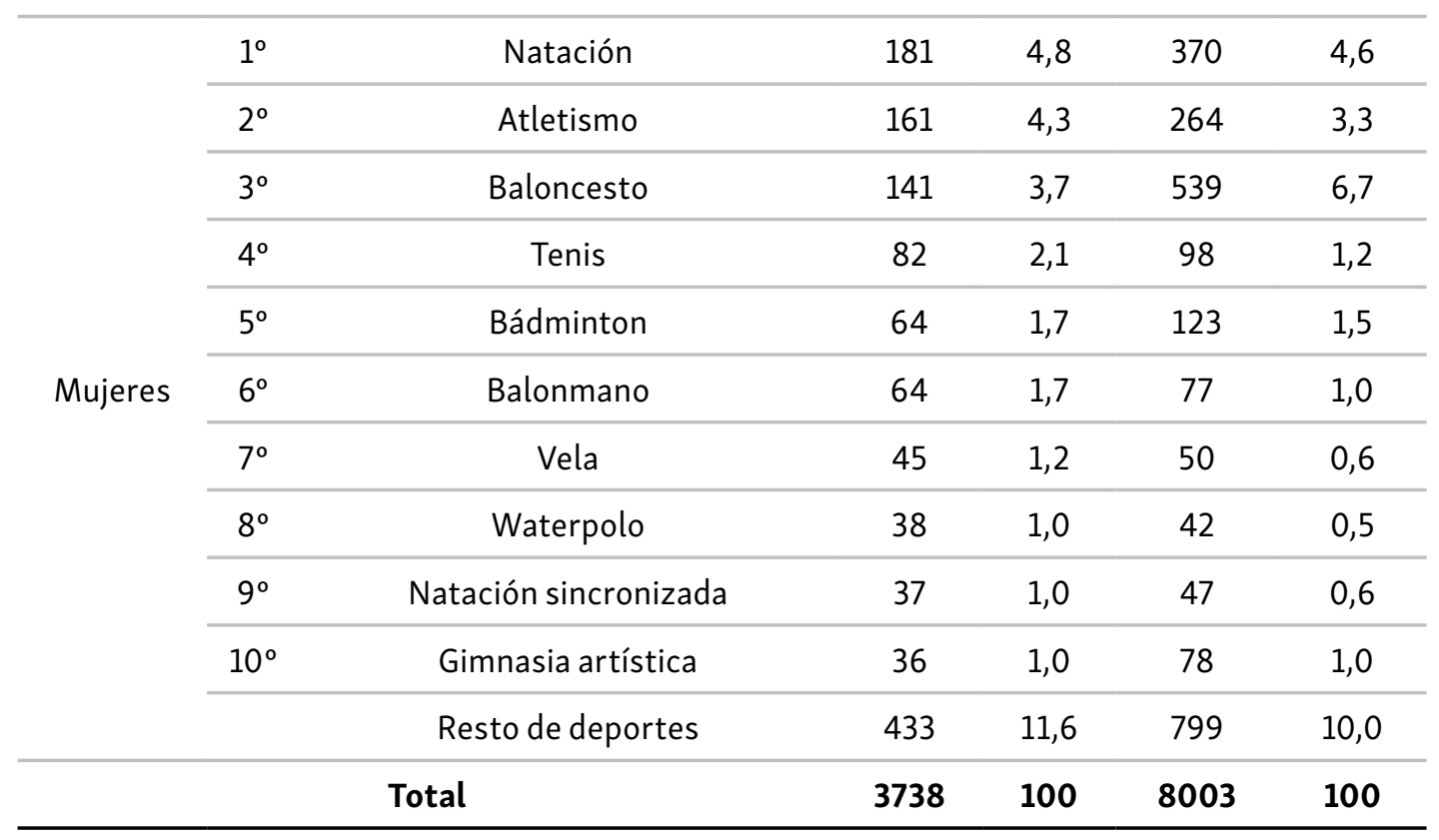

$x^{2}=0,0001$

Tabla 5. Diez eventos deportivos con mayor cobertura masculina y femenina

Fuente: Elaboración propia.

La cobertura visual desglosada por sexo indica que se otorga más presencia a deportes considerados apropiados para cada sexo. En el baloncesto, a pesar de la medalla de plata de las atletas españolas y la de bronce de los varones, las imágenes masculinas $(1635,20,4 \%)$ triplican a las femeninas (539, 6,7\%). Lo mismo ocurre en el fútbol. Carece de participación española en ambos sexos, pero la cobertura visual masculina alcanza 6,2\% del total (495 imágenes) frente a 0,8\% femenino (30 imágenes). En atletismo la participación española se saldó con un oro femenino, que no fue suficiente para igualar en cobertura ni imágenes a la plata masculina. Los hombres tuvieron más del triple de cobertura que las mujeres $(9,9 \%$ frente a 3,3\% del total). Similar fue el caso del taekwondo, con una medalla de plata femenina y una de bronce masculina y más del doble de imágenes masculinas que femeninas (27 frente a 65) o la halterofilia, con un bronce femenino y más del doble de imágenes masculinas (126 frente a 23). También ocurrió en otros deportes tradicionalmente masculinos, como el waterpolo o el tiro. El equipo español femenino alcanza mayores logros, pero los atletas varones consiguieron mayor cobertura en todos ellos. En el caso opuesto encontramos que las mujeres tienen una presencia superior en deportes como la gimnasia artística, a pesar de haber mayor participación masculina que femenina (78 imágenes femeninas y 22 masculinas) o el vóley playa, con la misma participación en ambos sexos (72 imágenes femeninas y 27 masculinas) y sin medallas. 


\begin{tabular}{ccccc} 
& \multicolumn{2}{c}{ Mujeres } & \multicolumn{2}{c}{ Hombres } \\
\cline { 2 - 5 } Fotografía & $\mathbf{N}$ & $\%$ & $\mathbf{N}$ & $\%$ \\
\hline Deportiva & 1111 & 89,9 & 2130 & 90,8 \\
\hline No deportiva & 125 & 10,1 & 216 & 9,2 \\
\hline Total & 1236 & 100 & 2346 & 100 \\
\hline
\end{tabular}

$\chi^{2}=0,05$

Tabla 6. Contenido deportivo de la fotografía por sexo

Fuente: Elaboración propia.

Los deportes considerados neutros en función del sexo (tenis o golf) siguen viéndose como masculinos. Las habilidades y atributos que implican favorecen más a los deportistas varones en su cobertura, que pasan a convertirse en los referentes por excelencia de tales disciplinas (Angelini, 2008). El tenis masculino alcanza $8,9 \%$ de la cobertura visual total frente a solo $1,2 \%$ femenino, y el golf masculino alcanza más del doble de imágenes que el femenino ( $1,4 \%$ frente a $0,6 \%$ femenino).

\section{Contenido de las fotografías}

En lo que respecta a si existe una sobrerrepresentación de imágenes deportivas masculinas, se encuentran porcentajes similares: las imágenes deportivas femeninas alcanzan $89,9 \%$ y las masculinas, 90,8\%. Las imágenes extradeportivas femeninas superan levemente en porcentaje a las masculinas (10,1\% frente a 9,2\%). En números totales, tanto las imágenes deportivas como no deportivas masculinas superan a las femeninas (tabla 6).

\section{Tipo de acción en la imagen en función del sexo}

Las mujeres son presentadas de forma activa en $57,3 \%$ y pasiva en $36,1 \%$. En el caso masculino el carácter activo se muestra en $62,1 \%$ y el pasivo, en $30 \%$ (tabla 7 ). Los hombres son mostrados en casi cinco puntos porcentuales más en imágenes activas, en plena competición o entrenando; las mujeres, en imágenes pasivas y estáticas, sin desempeñar su profesión.

\begin{tabular}{ccccc} 
& \multicolumn{2}{c}{ Mujeres } & \multicolumn{2}{c}{ Hombres } \\
\cline { 2 - 5 } & $\mathbf{N}$ & $\%$ & $\mathbf{N}$ & $\%$ \\
\hline Activa & 729 & 57,3 & 1531 & 62,1 \\
\hline Pasiva & 458 & 36,1 & 753 & 30,5 \\
\hline No se aprecia & 84 & 6,6 & 183 & 7,4 \\
\hline Total & 1271 & 100 & 2467 & 100 \\
\hline
\end{tabular}

$x^{2}=0,005$

Tabla 7. Tipo de acción del deportista por sexo

Fuente: Elaboración propia. 


\section{Presencia de sesgos y estereotipos de género en las imágenes}

Según vemos en la tabla 8, 10,9\% de las noticias femeninas tiene estereotipos de género en las imágenes y apenas un $2,2 \%$ de las masculinas. Del total de noticias con estereotipos ( $n=193), 72,0 \%$ se refieren a mujeres y $27,9 \%$, a hombres.

Si clasificamos los estereotipos presentes en las imágenes (tabla 9), encontramos un porcentaje concentrado en el marco de sexualización (22,7\%): casi todas son fotografías femeninas con encuadres de cámara inapropiados (15\%), principalmente en vóley playa femenino y atletismo, al centrar el punto focal en el pecho y en las nalgas, seguido de cuerpos desnudos o semidesnudos $(4,1 \%)$ y poses sugerentes $(3,6 \%)$. Este tipo de noticias se encontró en todos los medios, con ejemplos como "Las más bellas de los Juegos" (2016) y "Los selfies íntimos de la deportista expulsada por un escándalo sexual" (2016) en Marca o "Milica Dabovic, la deportista de Río que calienta Instagram" (2016) en Mundo Deportivo, con imágenes sexualizadas femeninas extraídas en su mayoría de sus redes sociales. En este grupo no se encontraron imágenes masculinas de cuerpos desnudos o semidesnudos. Las imágenes que incluyen marcos de sexualización como semidesnudez o poses sugerentes son principalmente de carácter no deportivo, extraídas de campañas publicitarias o de redes sociales de las atletas.

El siguiente estereotipo más habitual es la presencia de imágenes humillantes $(20,2 \%)$, captando un momento en el que la expresión facial o corporal del deportista resulta denigrante o ridícula. El caso femenino de nuevo ocupa casi la totalidad (36 imágenes) frente a tres masculinas. Las fotografías estereotipadas que muestran al deportista expresando emoción (llanto) alcanzan 15,6\% del total ( 25 femeninas y cinco masculinas).

Las imágenes que agrupan varios estereotipos se situarían en cuarto lugar, con 10,9\% del total. Integran varios aspectos de sexualización, como cuerpos semidesnudos, belleza y poses sugerentes. Destacan las relativas al baloncesto masculino, donde aparecen cheerleaders femeninas con vestimentas y posturas provocativas y un encuadre de cámara centrado en sus pechos y nalgas. Enla categoría varios, otras fotografías combinan estereotipos tales como maternidad y emoción. Las imágenes basadas en transmitir una marcada masculinidad a través de comunicación no verbal de agresividad y violencia alcanzan el 9,3\%, todas masculinas, principalmente sobre fútbol y boxeo. El grupo de ausencia femenina está formado por noticias que, estando referidas a atletas o equipos femeninos, no cuentan con imágenes sobre las deportistas $(8,8 \%)$ sino con genéricas de instalaciones, de sus compañeros masculinos o de su entrenador. 


\begin{tabular}{ccccc} 
& \multicolumn{3}{c}{ Mujeres } & \multicolumn{2}{c}{ Hombres } \\
\cline { 2 - 5 } & $\mathbf{N}^{\mathbf{0}}$ & $\%$ & $\mathbf{N}^{\circ}$ & $\%$ \\
\hline No & 1130 & 88,9 & 2403 & 97,4 \\
\hline Si & 139 & 10,9 & 54 & 2,2 \\
\hline No se aprecia & 2 & 0,2 & 10 & 0,4 \\
\hline Total & 1271 & 100 & 2467 & 100 \\
\hline
\end{tabular}

$\chi^{2}=0,0001$

Tabla 8. Presencia de sesgos y estereotipos en las imágenes

Fuente: Elaboración propia.

Las noticias sobre familia y maternidad representan 7,8\% del total de noticias con imágenes estereotipadas (17 femeninas). Destacan varias noticias sobre la deportista rusa Yulia Stepanov, mostrada en su casa alimentando a su hijo, y de la atleta Maialen Chourraut. Su reciente maternidad pasa a ser el elemento informativo central de la noticia y no sus opciones a medalla de oro, finalmente conseguida. "Mamá, no te saltes una puerta" (Mundo Deportivo, 2016) o "Maialen Chourraut, una mamá a contracorriente" (Marca, 2016) muestran a la deportista abrazando a su hija. Se encontraron tres imágenes con referencias a la paternidad, todas sobre el nadador Michael Phelps, aunque en las imágenes es su esposa quien espera al campeón con el niño en brazos. Esta subcategoría también incluye imágenes sobre futuras bodas y relaciones sentimentales y, en todas, a la protagonista le piden matrimonio. Esta faceta personal no se encontró para deportistas varones. En último lugar, las imágenes sobre belleza y apariencia física (4,7\% de las informaciones) están asociadas únicamente con mujeres. Las deportistas aparecen mostrando sus uñas pintadas, detalles sobre su delicado vestuario o en primeros planos -tanto de las atletas como de aficionadas-, descritas como bellezas.

Al desglosar todos estos estereotipos, las diferencias entre los sexos se amplían todavía más. En las noticias masculinas hay un 18,7\% de estereotipos sobre varones, pero se incluyen asimismo los femeninos en un $81,3 \%$ de los casos, lo que no sucede a la inversa. Así, se refuerzan permanentemente estereotipos tradicionales de género, en las informaciones concernientes tanto a los hombres como a las mujeres. 


\begin{tabular}{ccccc} 
& Mujeres & Hombres & \multicolumn{2}{c}{ TOTAL } \\
\cline { 2 - 5 } Estereotipos presentes en las imágenes & No & $\mathbf{N}^{\mathbf{0}}$ & $\mathbf{N}^{\mathbf{0}}$ & $\%$ \\
\hline Actitud agresiva o violenta & 0 & 18 & 18 & 9,3 \\
\hline Ausencia femenina & 17 & 0 & 17 & 8,8 \\
\hline Imagen degradante/vejatoria & 35 & 4 & 39 & 20,2 \\
\hline Expresión de las emociones (llorar) & 25 & 5 & 30 & 15,6 \\
\hline Maternidad y familia & 12 & 3 & 15 & 7,8 \\
\hline Belleza & 9 & 0 & 9 & 4,7 \\
\hline Marco de sexualización: & & & & \\
\hline Cuerpo desnudo o semidesnudo & 6 & 2 & 8 & 4,1 \\
\hline Pose sugerente & 7 & 0 & 7 & 3,6 \\
\hline Enfoque/encuadre inapropiado & 29 & 0 & 29 & 15,0 \\
\hline Varios & 17 & 4 & 21 & 10,9 \\
\hline Total & 157 & 36 & 193 & 100 \\
\hline \% & 81,3 & 18,7 & & 100 \\
\hline
\end{tabular}

Tabla 9. Tipo de sesgos y estereotipos de género en las imágenes según el sexo

Fuente: Elaboración propia.

\section{DISCUSIÓN Y CONCLUSIONES}

Siguiendo los trabajos previos sobre infrarrepresentación femenina en los medios deportivos, el objetivo de este estudio era conocer la representación fotográfica de las y los atletas para comprobar si se avanza hacia una mayor equidad de género tanto en la cantidad de cobertura como en su contenido. De las cinco hipótesis establecidas, se verificaron cuatro.

Se confirma la hipótesis 1, que predecía que las mujeres están infrarrepresentadas tanto en el número como en la extensión de las fotografías (Godoy-Pressland \& Griggs, 2014). El porcentaje de cobertura en el número y tamaño fue mayor de lo esperado en los atletas varones (casi 70\%) e inferior en las mujeres (no superaban el 30\%). Esto contribuye a invisibilizar a la mujer en el deporte, al transmitirse un mensaje de menor interés deportivo femenino (Delorme \& Testard, 2015). También fortalece la hegemonía masculina en la cobertura fotográfica de unos medios que conforman el grueso de la prensa deportiva española con una innegable influencia en el deporte de élite, así como en el no profesional. Estos hallazgos respaldan los estudios anteriores sobre la infrarrepresentación femenina en los medios deportivos (Fink \& Kensicki, 2002), aunque no coinciden con algunas 
investigaciones previas que encontraron una cobertura más favorable en mega eventos como los Juegos Olímpicos (Eagleman et al., 2014; Godoy-Presland \& Griggs, 2014) debido a una tendencia al nacionalismo que ofrece mayor visibilidad a las atletas (Delorme \& Testard, 2015).

También se confirman diferencias significativas entre el sexo y el deporte representado en los medios ( $\mathrm{H} 2: \chi^{2}=713,176 \mathrm{df}=42, \mathrm{p}<0,0001$ ). Se rechaza la hipótesis nula y se acepta la hipótesis 2 , que afirma que las deportistas tienen mayor nivel de cobertura visual en los deportes considerados apropiados femeninos y los varones en otros considerados masculinos (Koivula, 1999; Jones, 2006).

No se aprecian diferencias significativas entre el sexo del deportista y el tipo de fotografía, por lo que se rechaza la hipótesis $3\left(\chi^{2}=0,771 \mathrm{df}=1, p<0,05\right)$ y se acepta la hipótesis nula, al no encontrarse diferencias en los marcos de contexto, como evidencian Cranmer et al. (2014). Las mujeres son representadas en contextos deportivos de forma similar a los hombres ( 89,9 frente a 90,8\%), habiendo poca presencia de los no deportivos para ambos casos ( $10,1 \%$ femenino y $9,2 \%$ masculino). Estos resultados contradicen estudios previos que sugieren que se les niega a las mujeres dicho contexto, favoreciéndose el extradeportivo (Hardin et al., 2005; Fink \& Kensicki, 2002).

La hipótesis 4 queda asimismo validada ( $\left.\mathrm{H} 4: \mathrm{\chi}^{2}=11,70 \mathrm{df}=2, \mathrm{p}<0,005\right)$, al percibirse diferencias significativas entre las categorías sexo del deportista y el tipo de acción desempeñada en la imagen. Se confirma una representación de las deportistas en una actitud pasiva en mayor medida que los varones (36\% frente a $30 \%$ ). Ellos son mostrados más activamente (62\% frente a $57 \%$ ), tal como describen estudios previos (Fink \& Kensicki, 2002; Lynn et al., 2004; Litchfield \& Kavanagh, 2019).

Por último, la hipótesis 5 también queda validada ampliamente, pues existen diferencias significativas en la correlación entre el sexo del deportista y la presencia de estereotipos de género $\left(\chi^{2}=132,330 \mathrm{df}=2, \mathrm{p}<0,0001\right)$. Las imágenes femeninas incluyen más sesgos y estereotipos de género que las masculinas (10,9\% frente a $2,2 \%)$, lo que supone que existen más probabilidades de estereotipos de género en las imágenes cuando son protagonizadas por mujeres. Esto se confirma mediante el análisis de encuadres visuales (Coleman, 2010), que muestra la presencia de marcos de sexualización femenina en el contexto deportivo (Cranmer et al., 2014) mediante imágenes con un enfoque inapropiado (Bissell \& Duke, 2007; Wasike, 2017), cuerpos desnudos o semidesnudos (Daniels \& Wartena, 2011) y poses sugerentes (Duncan, 1990) que buscan transmitir incitación sexual (King, 2007; Weber \& Carini, 2013). También se encuentran marcos que trivializan los logros femeninos mediante imágenes de debilidad y expresión de las emociones frente a las de fuerza y agresividad masculina (Borcila, 2000), más imágenes degradantes 
femeninas, así como de aspectos relativos a la familia, a la maternidad, a las relaciones sentimentales o a la belleza (López-Diez, 2011). Tales encuadres visuales contribuyen a una representación ambivalente de estas mujeres y a transmitir que, aunque ambos sexos pueden practicar deporte, ellos son atléticos y poderosos y ellas, estéticas y débiles.

En resumen, los medios deportivos digitales españoles durante los Juegos Olímpicos de Río muestran un desequilibrio en la cobertura visual de cada sexo, dado que contribuyen a la infrarrepresentación femenina en las imágenes (GodoyPressland \& Griggs, 2014). Transmiten marcos de ambivalencia al presentar a las deportistas en deportes considerados apropiados para cada sexo (Jones, 2006) y de manera pasiva en mayor medida que a los deportistas (Fink \& Kensicki, 2002; Lynn et al., 2004; Delorme \& Testard, 2015). Aunque no se han encontrado diferencias en la representación de ambos sexos en el contexto deportivo (Cranmer et al., 2014) no ha sido así al transmitir sesgos y estereotipos, basados principalmente en la sexualización de las mujeres (Duncan, 1990; Bissell \& Duke, 2007; Daniels \& Wartena, 2011; Wasike, 2017), pero también mediante imágenes degradantes, expresión de las emociones y debilidad femeninas frente a agresividad masculina (Borcila, 2000; Jones, 2006). Del mismo modo, se resaltan aspectos de la vida privada, como la maternidad y las relaciones sentimentales (López-Diez, 2011). Todo ello contribuye a trivializar el deporte femenino y a reforzar la hegemonía masculina al transmitir a las audiencias la idea de que el deporte practicado por mujeres es menos relevante. Así, la sociedad en general, especialmente las mujeres y niñas, reciben el mensaje de que la práctica profesional y las habilidades femeninas no son suficientes para aparecer en los medios, por lo que han de ser completadas con sensualidad, belleza y otros aspectos extradeportivos, lo que influirá en su desarrollo profesional (Weber \& Carini, 2013).

Futuras investigaciones podrían profundizar en los marcos mediáticos para revelar aspectos cualitativos de la representación; por ejemplo, cómo se muestra la masculinidad en deportes considerados como apropiados femeninos cuando los practican varones, como la gimnasia artística, o analizar la cobertura de otros macroeventos para establecer comparaciones entre estos o entre países, en búsqueda de diferencias entre equipos nacionales y extranjeros en función del sexo. Otra línea podría ampliar los estudios sobre cobertura fotográfica en los nuevos medios digitales e incluso a sus redes sociales, algunas tan visuales como Instagram, para ver si las diferencias sexuales persisten o si ofrecen mayores cotas de equidad de género. Ello permitirá profundizar en la realidad de la cobertura femenina y promover desde instituciones, organismos y medios medidas para avanzar en una representación más equilibrada del deporte femenino. 


\section{REFERENCIAS}

Ada-Lameiras, A. (2019). Análisis del Twitter de los medios deportivos en España con perspectiva de género: la invisibilización de las mujeres deportistas (Twitter analysis of sports media in Spain with a gender perspective: the invisibility of sportswomen) (Doctoral dissertation, Universidad de Vigo). http://hdl.handle.net/11093/1348

Alfaro, E., Bengoechea, M., \& Vázquez, B. (2011). Hablamos de Deporte. En femenino y masculino (Let us talk about feminine and masculine sport). Instituto de la Mujer. https://www.inmujeres.gob.es/areasTematicas/AreaDeporte/docs/MaterialesDidacticos/ HablamosDeporte.pdf

Andrew, D., Pedersen, P., \& MacEvoy, C. (2011). Research Methods and Design in Sport Management. Human Kinetics.

Angelini, J. (2008). Television sports and athlete sex: Looking at the differences in watching male and female athletes. Journal of Broadcasting and Electronic Media, 52(1), 16-32. https://doi.org/10.1080/10934520701820752

Angelini, J. \& Billings, A. (2010). An Agenda That Sets the Frames: Gender, Language, and NBC's Americanized Olympic Telecast. Journal of Language and Social Psychology, 29(3), 363-385. https://doi.org/10.1177/0261927X10368831

Barthes, R. (1977). Image, Music, Text. Fontana.

Berstein, A. \& Kian, E. T. (2013). Gender and sexualities in sport media. In P. Pedersen (Ed.), Routledge Handbook of Sport Communication (pp. 319-327). Routledge.

Billings, A. \& Eastman, S. T. (2003). Framing identities: Gender, ethnic, and national parity in network announcing of the 2002 Winter Olympics. Journal of Communication, 53(4), 569-586. https://doi.org/10.1111/j.1460-2466.2003.tb02911.x

Bissell, K. \& Duke, A. (2007). Bump, Set, Spike: An Analysis of Commentary and Camera Angles of Women's Beach Volleyball During the 2004 Summer Olympics. Journal of Promotion Management, 13(1-2), 35-53. https://doi.org/10.1300/J057v13n01_04

Borcila, A. (2000). Nationalizing the Olympic Around and Away from "Vulnerable" Bodies of Women: The NBC Coverage of the 1996 Olympics and Some Moments After. Journal of Sport E Social Issues, 24(2), 118-147. https://doi.org/10.1177/0193723500242003

Bryman, A. (2016). Social Research Methods. Oxford University Press.

Coche, R. \& Tuggle, C. (2017). Men or Women, Only Five Olympic Sport Matter: A Quantitative Analysis of NBC's Prime-Time Coverage of the Rio Olympics. Electronic News, 12(4), 199-217. https://doi.org/10.1177/1931243117739061

Coleman, R. (2010). Framing the pictures in our heads: Exploring the framing and agendasetting effects of visual images. In P. D’Angelo \& J. Kuypers (Eds.), Doing News Framing Analysis: Empirical and Theoretical Perspectives (pp. 233-262). Routledge.

Cranmer, G., Brann, M., \& Bowman, N. (2014). Male Athletes, Female Aesthetics: The Continued Ambivalence Toward Female Athletes in ESPN's The Body Issue. International Journal of Sport Communication, 7(2), 145-165. https://doi.org/10.1123/IJSC.2014-0021

Comité Olímpico Español. (2016). Río 2016. https://www.coe.es/juegos/ 
Dafferner, M., Campagna, J., \& Rodgers, R. (2019). Making gains: Hypermuscularity and objectification of male and female Olympic athletes in Sports Illustrated across 60 years. Body Image, 29, 156-160. https://doi.org/10.1016/j.bodyim.2019.04.001

Daniels, E. \& Wartena, H. (2011). Athlete or Sex Symbol: What Boys Think of Media Representations of Female Athletes. Sex Roles, 65(7-8), 566-579. https://doi.org/10.1007/s11199-011-9959-7

Davis, K. \& Tuggle, C. (2008). A Gender Analysis of NBC's Coverage of the 2008 Summer Olympics. Electronic News, 6(2), 51-66. https://doi.org/10.1177/1931243112452261

Delorme, N. \& Testard, N. (2015). Sex equity in French newspaper photographs: A content analysis of 2012 Olympic Games by L'Equipe. European Journal of Sport Science, 15(8), 757-763. https://doi.org/10.1080/17461391.2015.1053100

Dixon, J. E. (2008). Who took that photo? A content analysis of front page online newspaper photographs. University of Nevada.

Duncan, M. C. (1990). Sports Photographs and Sexual Difference: Images of Women and Men in the 1984 and 1988 Olympic Games. Sociology of Sport Journal, 7(1), 22-43.

https://doi.org/10.1123/ssj.7.1.22

Eagleman, A., Burch, L., \& Vooris, R. (2014). A Unified Version Of London 2012: New-Media Coverage of Gender, Nationality, and Sport For Olympics Consumers in Six Countries. Journal of Sport Management, 28(4), 457-470. https://doi.org/10.1123/jsm.2013-0151

Fink, J. \& Kensicki, L. J. (2002). An Imperceptible Difference: Visual and Textual Constructions of Femininity in Sports Illustrated and Sports Illustrated For Women. Mass Communication and Society, 5(3), 317-339. https://doi.org/10.1207/s15327825mcs0503_5

Franquet, R., Luzón, V., \& Ramajo, N. (2007). La información en los principales medios de comunicación online. Estudiar la representación de género (News in the Principal On-line Mass Media. Studying Gender Representation). Zer: Revista de estudios de comunicación= Komunikazio ikasketen aldizkaria, 12(22), 267-282. https://doi.org/10.1387/zer.3688

Greer, J., Hardin, M., \& Homan, C. (2009). "Naturally" Less Exciting? Visual Production of Men's and Women's Track and Field Coverage During the 2004 Olympics. Journal of Broadcasting \& Electronic Media, 53(2), 173-189. https://doi.org/10.1080/08838150902907595

Godoy-Pressland, A. \& Griggs, G. (2014). The photographic representation of female athletes in the British print media during the London 2012 Olympic Games. Sport in Society: Cultures, Commerce, Media, Politics, 17(6), 808-823. https://doi.org/10.1080/17430437.2014.882908

Goffman, E. (1974). Frame analysis. An essay on the organization of experience. Harvard University Press.

Hardin, M., Lynn, S., \& Walsdorf, K. (2005). Challenge and Conformity on “Contested Terrain”: Images of Women in Four Women's Sport/Fitness Magazines. Sex Roles, 53(1-2), 105-117. https://doi.org/10.1007/s11199-005-4285-6

Hardin, M., Lynn, S., Walsdorf, K., \& Hardin, B. (2002). The Framing of Sexual Difference in SI for Kids Editorial photos. Mass Communication \& Society, 5, 341-359. https://doi.org/10.1207/S15327825MCS0503_6

Hargreaves, J. \& Anderson, E. (2014). Routledge Handbook of Sport, Gender and Sexuality. Routledge. 
Jones, D. (2006). The representation of female athletes in online images of successive Olympic games. Pacific Journalism Review, 12(1), 108-129. https://doi.org/10.24135/pjr.v12i1.848

King, C. (2007). Media Portrayals of Male and Female Athletes. A Text and Pictures Analysis of British National Newspaper Coverage of the Olympic Games since 1948. International Review for the Sociology of Sport, 42(2), 187-199. https://doi.org/10.1177/1012690207084751

Koivula, N. (1999). Gender stereotyping in televised media sport coverage. Sex Roles, 41(7-8), 589-604. https://doi.org/10.1023/A:1018899522353

Krippendorff, K. (1990). Metodología de análisis de contenido: teoría y práctica (Content Analysis. An Introduction to its Methodology). Paidós.

Las más bellas de los Juegos (The Game’s Prettiest). (2016, August 03). Marca. https://www.marca.com/juegos-olimpicos/album/2016/08/03/57a0d846e5fdeaa26b8b463d.html

Litchfield, C. \& Kavanagh, E. (2019). Twitter, Team GB and the Australian Olympic Team: representations of gender in social media spaces. Sport in Society. Cultures, Commerce, Media, Politics, 22(7), 1148-1164. https://doi.org/10.1080/17430437.2018.1504775

López-Diez, P. (2011). Deporte y mujeres en los medios de comunicación: sugerencias y recomendaciones (Sport and Women in Mass Media. Suggestions and Recommendations). Consejo Superior de Deporte.

Los selfies íntimos de la deportista expulsada por un escándalo sexual (The intimate selfies of the athlete expelled by a sex scandal). (2016, August 16). Marca. https://www.marca.com/ juegos-olimpicos/album/2016/08/15/57b223e2468aebaf348b45d6.html

Lynn, S., Hardin, M., \& Walsdorf, K. (2004). Selling(out) the Sporting Woman: Advertising Images in Four Athletic magazines. Journal of Sport Management, 18(4), 335-349. https://doi.org/10.1123/jsm.18.4.335

Marca (2016, August 12). Maialen Chourraut, una mamá a contracorriente (Maialen Chourraut, a mother against the tide). Marca. https://www.marca.com/juegos-olimpicos /2016/08/11/57acbc2a468aebc5158b45a7.html

McCombs, M. (2006). Estableciendo la agenda. El impacto de los medios en la opinión pública y en el conocimiento (Setting the Agenda: The News Media and Public Opinion). Paidós Comunicación.

Milica Dabovic, la deportista de Río que calienta Instagram (Milica Dabovic, the athlete from Rio who heats Instagram). (2016, August 09). Mundo Deportivo. https://www.mundodeportivo.com/vaya-mundo/20160809/403801515161/milicdabovic-basquet-serbio-rio-fotos.html

Mulvey, L. (1999). Visual Pleasure and Narrative Cinema. In L. Braudy \& M. Cohen (Eds.), Film Theory and Criticism: Introductory Readings (pp. 833-844). Oxford UP.

Mundo Deportivo (2016, October 8). Mamá, no te saltes una puerta (Mum, don't miss a door). Mundo Deportivo. https://www.mundodeportivo.com/ juegosolimpicos/20160812/403867315378/mama-no-te-saltes-una-puerta.html

Muñoz-Muñoz, A. M. \& Salido-Fernández, J. (2018). Tratamiento informativo de las esposas y novias (WAG'S) de los deportistas en la prensa digital deportiva española (Informative treatment of sportsmen's wives and girlfriends (WAGs) in Spanish sport digital press). El Profesional de la Información, 27(2), 331-340. https://doi.org/10.3145/epi.2018.mar.11 
Musto, M., Cooky, C., \& Messner, M. (2017). “From Fizzle to Sizzle!” Televised Sports News and the Production of Gender-Bland Sexism. Gender \& Society, 31(5), 573-596. https://doi.org/10.1177/0891243217726056

Pedersen, P. M. (2002). Examining Equity in Newspaper Photographs: A Content Analysis of the Print Media Photographic Coverage of Interscholastic Athletics. International Review for the Sociology of Sport, 37(3-4), 303-318. https://doi.org/10.1177/1012690202037004895

Perrino-Peña, M. \& Pascual Fibla, S. (2019). Análisis de noticias de deportistas femeninas en los Juegos Olímpicos de Río 2016 en la prensa digital (Analysis of News of Female Athletes at the Rio 2016 Olympic Games in the Digital Press). Revista Española de Educación Física $y$ Deportes, (426), 145-153. https://www.reefd.es/index.php/reefd/article/view/773

Reese, S. (2001). Framing Public Life: A Bridging Model for Media Research. In S. Reese, O. Gandy \& A. Grant (Eds.), Framing public life: Perspectives on media and our understanding of the social world (pp. 7-31). Lawrence Erlbaum Associates.

Riffle, D., Lacy, S., \& Fico, F. (2005). Analyzing Media Messages: Using Quantitative Content Analysis in Research. Lawrence Erlbaum Associates Publishers.

Rose, G. (2016). Visual Methodologies: An Introduction to Researching with Visual Materials. SAGE.

Sanz-Garrido, B. (2015). Las mujeres deportistas en la prensa: los Juegos Olimpicos de Londres 2012 (Sportswomen in the Press: the London 2012 Olympics). Editorial UOC.

Salido-Fernández, J. \& Muñoz-Muñoz, A. M. (2021a). Representación mediática de las deportistas en los Juegos Olímpicos: una revisión sistemática (Media Representation of Women Athletes at the Olympic Games: A Systematic Review). Apunts. Educación fisica $y$ deportes, 146, 32-41. https://doi.org/10.5672/apunts.2014-0983.es.(2021/4).146.04

Salido-Fernández, J. \& Muñoz-Muñoz, A. M. (2021b). Men's and Women's Basketball Coverage in the Spanish Digital Press During the 2016 Rio Olympics. Journalism Practice. https://doi.org/10.1080/17512786.2021.2004199

Smith, L. R. \& Bissell, K. (2014). Nice Dig! An analysis of the verbal and visual coverage of men's and women's beach volleyball during the 2008 Olympic Games. Communication $\mathcal{E}$ Sport, 2(1), 48-64. https://doi.org/10.1177/2167479512467771

Strinati, D. (2000). An introduction to studying popular culture. Routledge.

Tankard, J. (2001). The empirical approach to the study of media framing. In S. Reese, O. Gandy, \& A. Grant (Eds.), Framing public life: Perspectives on media and our understanding of the social world (pp. 7-31). Lawrence Erlbaum Associates.

Trailblazing Tokyo looking ahead with dazzling innovation. (2020, July 23). International Olympic Committee. https://olympics.com/ioc/news/trailblazing-tokyo-looking-aheadwith-dazzling-innovation

Tuchman, G. (1978). Introduction: The symbolic annihilation of women by the mass media. In G. Tuchman, A. Daniels, \& J. Benet (Eds.), Hearth and Home: Images of Women in the Mass Media (pp. 3-38). Oxford University Press. 
Ramón-Vegas, X. (2012). La cobertura deportiva y el principio deontológico de la justicia. Revisión de la literatura sobre las representaciones mediáticas de género, nacionalidad, raza y discapacidad en los Juegos Olímpicos (Sports Coverage and the Deontological Principle of Justice. Review of the Literature on Media Representations of Gender, Nationality, Race, and Disability in the Olympic Games). In Proceedings of the IV Congreso Internacional Latina de Comunicación Social, Universidad de La Laguna. http://www.revistalatinacs.org/12SLCS/2012_actas.html

Vincent, J. (2004). Game, Sex, and Match: The Construction of Gender in British Newspaper Coverage of the 2000 Wimbledon Championship. Sociology of Sport Journal, 21(4), 435-456. https://doi.org/10.1123/ssj.21.4.435

Wasike, B. (2017). Jocks versus jockettes: An analysis of the visual portrayal of male and female cover models on sports magazines. Journalism, 21(10), 1432-1449. https://doi.org/10.1177/1464884917716818

Weber, J. \& Carini, R. (2013). Where are the Female Athletes in Sports Illustrated? A Content Analysis of Covers (2000-2011). International Review for the Sociology of Sport, 48(2), 196-203. https://doi.org/10.1177/1012690211434230

Wimmer, R. \& Dominick, J. (2011). Mass Media Research. An Introduction. Wadsworth Cengage Learning.

Zelizer, B. (2005). Journalism Through the Camera's Eye. In S. Allan (Ed.), Journalism: Critical Issues (pp. 167-176). Open University Press.

\section{SOBRE LAS AUTORAS}

ANA M. MUÑoz-MUÑoz, Profesora Titular del Departamento de Información y Comunicación de la Universidad de Granada y miembro del Instituto Universitario de Investigación de Estudios de las Mujeres y de Género de la misma. Su investigación se centra en la documentación desde una perspectiva de género. Líneas de investigación: Mujeres y ciencia: producción científica desde una perspectiva de género; El cuerpo y sus significados: la imagen de la mujer en prensa, fotografía y publicidad; Fuentes de información para los estudios de las mujeres y de género.

iD https://orcid.org/0000-0003-4575-698X

JUANA SALIDO-FERNÁNDEZ, Licenciada en Periodismo por la Universidad de Sevilla e investigadora predoctoral del Programa de Estudios de las Mujeres, Discursos y Prácticas de Género de la Universidad de Granada. Sus líneas de investigación incluyen: la representación femenina en los medios de comunicación, prensa deportiva y estudios del discurso mediático. Entre sus últimos trabajos destaca: Men's and Women's Basketball Coverage in the Spanish Digital Press During the 2016 Rio Olympic (2021). Actualmente es periodista en gabinete de comunicación institucional.

iD https://orcid.org/0000-0001-9107-300X 